\title{
Rare Association of Congenital Facial Palsy, Bilateral Microtia and Congenital Heart Disease
}

\author{
Rawat A $^{1}$, Bhil D'2, Javadekar BB ${ }^{3}$
}

\begin{abstract}
We report a case of a two day old female child with congenital facial palsy, bilateral microtia, congenital heart disease, renal ectopia and unilateral hypoplasia of depressor anguli oris muscle. These constellation of symptoms have not been found together in any case before. This unknown syndrome could be considered to be in a gray zone between Caylers Cardiofacial syndrome and Pearls syndrome.
\end{abstract}

Key words: Congenital facial palsy, Bilateral microtia, congenital heart disease, Hypoplsia of depressor anguli oris muscle, Pearl syndrome

\section{Introduction}

A symiacia symmetric facial appearance can be due to abnormality in facial nerve innervation or abnormality of facial musculature, presence of both simultaneously is very uncommon phenomenon.It is seen in association with anomalies of external ear, inner ear or facial dysmorphismsMicrotia is an underdeveloped external ear and is usually a presentation of Meier-Gorlin syndrome, Treacher Collin syndrome, Craniofacial Microsomia ${ }^{1}$.Congenital facial palsy can be due to birth trauma or developmental anomaly, former being more common ${ }^{2}$. Hypoplasia of depressor anguli oris muscle is associated with anomalies of head and neck, heart,skeleton, genital urinary system and central nervous system.

The combined presentation of facial palsy, bilateral microtia, hyoplasia of depressor anguli oris muscle, renal anomaly with congenital heart disease is rare.

This case is being reported due to the rarity of such occurrence.

\section{The Case}

A two day old full term small for date female child was referred for deviation of mouth while crying. No significant antenatal history of fever with rash, ingestion of teratogenic drugs like thalidomide, retinoic acid or misoprostol or radiation exposure was recalled by mother. Folic acid, iron and calcium supplementation was taken during pregnancy. No family history of congenital malformation present.Child was born to a 24 year old primigravida in a non-consanguineous marriage, delivered vaginally with vertex presentation without use of forceps or vacuum, cried immediately after birth. Her birth weight
${ }^{1}$ Dr. Aditi Rawat, MBBS. MD Resident, Department of Paediatrics, ${ }^{2} \mathrm{Dr}$. Dipika Bhil, MBBS. MD Resident, ${ }^{3} \mathrm{Dr}$. Bakul B Javadekar, MBBS. MD. Head of the department. All from the Department of Paediatrics, Shri Sayajirao General Hospital and Medical College, Vadodara, India.

\section{Address for correspondence \\ Dr. Aditi Rawat \\ E-mail : aditirawat0691@gmail.com}

\section{How to cite}

Rawat A, Bhil D, Javadekar BB. Rare Association of Congenital Facial Palsy, Bilateral Microtia and Congenital Heart Disease. J Nepal Paediatr Soc 2017;37(2):201-203.

doi: http://dx.doi.org/10.3126/jnps.v37i2.18077

This work is licensed under a Creative Commons Attribution 3.0 License.

$$
\text { (c) (i) }
$$




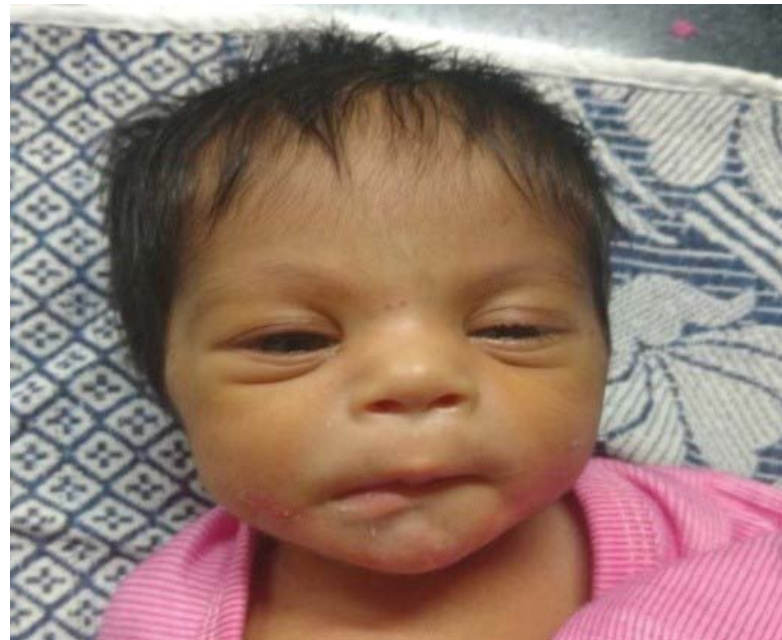

Fig 1a: Face at rest

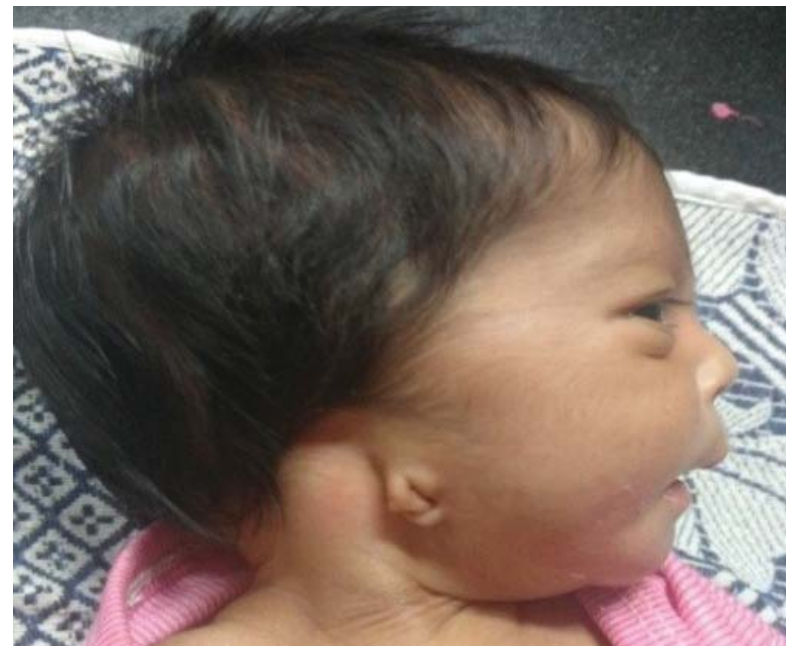

Fig 2a: Right side third degree microtia

was 2030 grams ( $<3^{\text {rd }}$ centile), head circumference was $32.5 \mathrm{~cm}$ (between $3^{\text {rd }}$ and $15^{\text {th }}$ centile), length was 47.5 $\mathrm{cm}\left(15^{\text {th }}\right.$ centile). General examination showed bilateral third degree microtia (Figures $2 a \& 2 b$ ), according to Hunter's Classification, in which there are some auricular structures visible but none of these structures confirms to recognized ear components. She also had right side congenital facial palsy (Figure 1a) manifested by absence of forehead wrinkles, absence of right nasolabialfold and inability to close right eye. Asymmetric crying facies (Figure 1a) was seen in which right lower lip was pulled down while crying which indicates hypoplsia of left depressor anguli oris muscle. Rest of the cranial nerves were normal on examination. The child did not have any other malformation on a detailed evaluation. Systemic examination revealed normal heart sounds.USG abdomen showed right kidney in right iliac fossa (simple renal ectopia) while left kidney was normal in shape size and position. Two-dimensional echocardiography was suggestive of congenital acaynotic heart disease in the

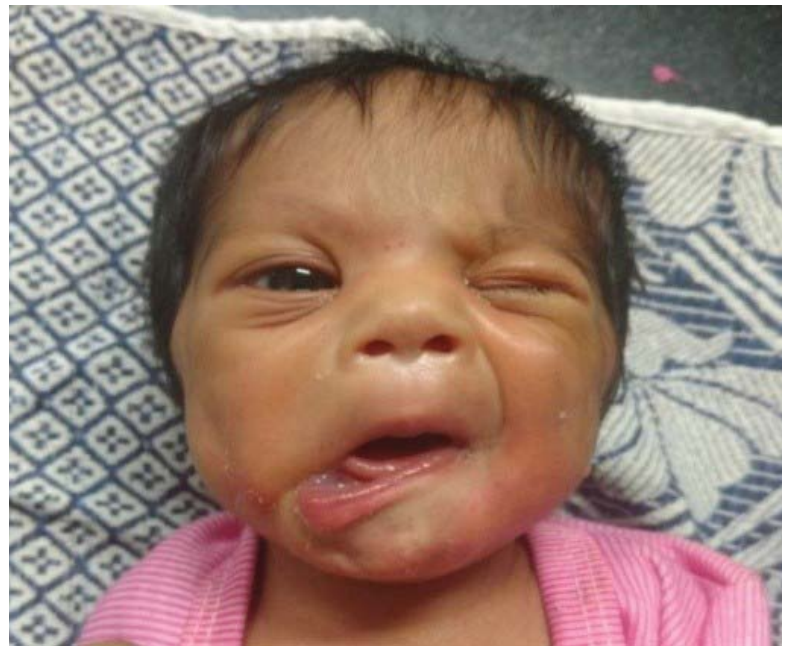

Fig 1b: Asymmetric crying facies

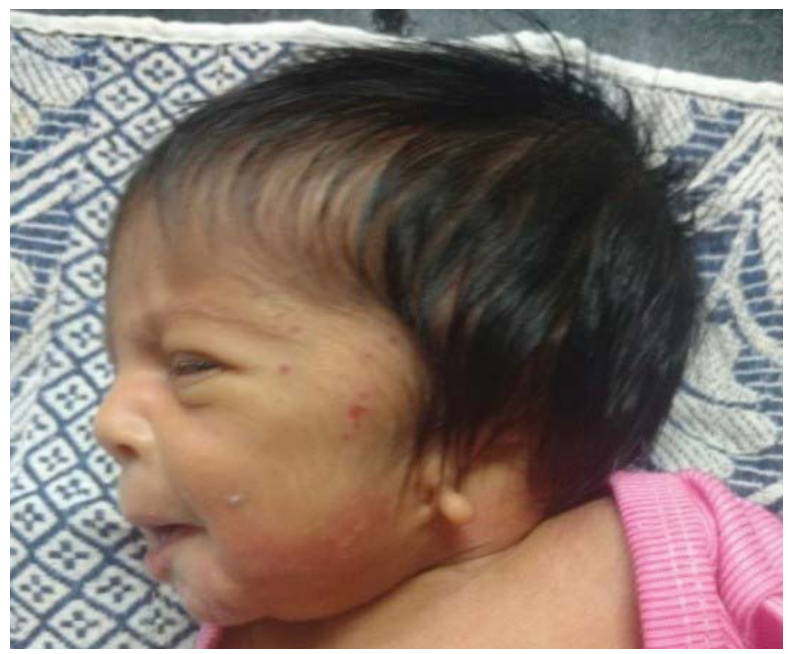

Fig 2b: Left side third degree microtia

form of patent ductus arteriosus measuring 1-2 $\mathrm{mm}$ at main pulmonary artery level and patent foramen ovale with left to right shunt which were still persistent after six months of follow up. MRI brain showed no abnormality. No chromosomal anomaly found on karyotyping.

\section{Discussion}

Microtia is a congenital anomaly of the ear that ranges in severity from mild structural abnormalities to complete absence of the ear, and can occur as an isolated birth defect or as part of a spectrum of anomalies or a syndrome. Existing data ${ }^{1}$ indicate that Mendelian inheritance is more likely in syndromic and familial cases of microtia, whereas multifactorial or polygenic causes are more probable in sporadic cases. Some important risk factors ${ }^{1}$ for above are low birth weight; maternal acute illness; gestational diabetes mellitus and consumption of teratogenic drugs like thalidomide ${ }^{3}$, retinoic $\mathrm{acid}^{4}$, alcohol. The only risk factor present in our case was low birth weight.Facial palsy ${ }^{2}$ can be congenital (due to 
birth traumas and genetic diseases) or acquired (due to infective, inflammatory, traumatic causes). Nonetheless, in approximately $40 \%-75 \%$ of the cases, the cause of unilateral facial paralysis still remains idiopathic. Birth trauma is the most common cause for congenital facial palsy although no such historywas present in this case. Syndromes usually seen in association with facial nerve palsy are Möbius ${ }^{2}$ syndrome and goldenhar ${ }^{5}$ syndrome but in the our case abducens nerve was normal, no cleft lip/palate seen and no ocular abnormalities were noted. Cayler Cardio-facial syndrome $e^{6,7,8}$ is a rare syndrome associated with congenital heart disease and hypoplasia of depressor anguli oris muscle. These children present with asymmetric crying faces but normal facies at rest. On FISH analysis it shows deletion of $22 \mathrm{q} 11.2$ chromosome in some cases.

Our case differs from this syndrome due to presence of microtia, unilateral facial palsy and renal anomaly along with what was described by Cayler et al.Pearl syndrome ${ }^{9}$ has a similar triad of congenital facial palsy, anotia, congenital heart disease. In the two cases described by Pearl, one girl had right side facial palsy and left sided anotia while the other girl had same anomalies to the left side. Both had ventricular septal defect with pulmonary stenosis. Our case had hypoplasia of depressor anguli oris, renal anomalies and bilateral deformity of ear in addition to the triad

\section{References}

1. Luquetti D, Heike C, Hing A, Cunningham M, Cox T. Microtia: Epidemiology and genetics.Am J Med Genet A 2012;158A(1):124-39. doi: 10.1002/ajmg.a.34352. Epub 2011 Nov 21

2. Ciorba A, Corazzi V, Conz V, Bianchini C, Aimoni C. Facial Nerve Paralysis in Children.World J Clin Cases 2015;16;3(12):973-9. doi: 10.12998/wjcc.v3.i12.973.

3. Lenz W. Chemicals and malformations in man. In Second International Conference on Congenital Malformations. New York: The International Medical Congress. (1963): 263-76

4. Lammer EJ, Chen DT, Hoar RM, Agnish ND, Benke PJ, Braun JT, et al. Retinoic acid embryopathy. N Engl J Med1985;313(14):837-41. described above.A similar case reported by Bhatnagar ${ }^{10}$ and Prasad had anotia on right side and microtia on left side, lower motor neuron weakness of facial nerve on right side, hypoplasia of left depressor anguli orismuscle and acyanotic heart disease (ventricular septal defect and small patent ductus arteriosus). No chromosomal anomaly found on karyotyping and FISH. Our case is similar to the above with addition of renal ectopia.I

In a study conducted by Lenz ${ }^{3}$ it was concluded that thalidomide ingestion between days 34 and 38 after the last menstrual period was usually associated with abnormalities of the ear and paralysis of seventh cranial nerve. Similarly, at this stage of gestation disturbance in the common pathway in the development of the facial nerve, the hyoid arch (from which the ear develops), and the cardiac primordial, which are in close anatomic proximity to each other may lead to this triad of anomaly.

\section{Conclusion}

The presence of congenital facial palsy, hypoplasia of depressor anguli oris, bilateral microtia, renal ectopia and congenital heart disease is a very uncommon association and this case shows features of Pearl syndrome overlapping with those of Caylers Cardiofacial syndrome. Since no specific risk factor or causative agent was found in this case and was concluded to be of unknown etiology.

5. Bretton Chappuis B, Engel E. Anotia, facial paralysis, heart abnormalities: Specific triad or variant of Goldenhar syndrome. Ann Genet 1989;32:52-4

6. Pawar, Sunil Jayaram et al. Cayler Cardio-Facial Syndrome: An Uncommon Condition in Newborns.Iran $J$ Pediatr2015;25(2):e502

7. Girisha KM, Phadke SR. Anotia and Facial Palsy: Unusual Features of Cardiofacial Syndrome.Indian J Pediatr 2005;72(6):525-26

8. Cayler, G. G. "Cardiofacial Syndrome. Congenital Heart Disease and Facial Weakness, a Hitherto Unrecognized Association.Arch DisChild1969;44(233):69-75.

9. Pearl W. Syndrome of anotia, facial paralysis, and congenital heart disease. J Pediatr(1984);105(3):441-2

10. Bhatnagar R, Prasad PL. Rare Association of Bilateral Anotia with Congenital Facial Palsy. J Nepal Paediatr Soc2015;35(2):195-97. 